\title{
Chronic scrotal hematocele: a rare entity and diagnostic dilemma
}

\author{
Abstract \\ Objective: A comprehensive literature review performed to highlight the clinical and \\ surgical aspect of chronic scrotal hematocele. \\ Material and method: The National Library of Medicine database searched for relevant \\ article using combination of key words: hematocele, scrotal hematocele, chronic hematocele \\ up to January 2017, irrelevant abstracts excluded and articles reviewed from the clinical, \\ radiological and pathological aspects. \\ Results and discussion:Chronic scrotal hematocele presented as slowly progressing \\ scrotal mass, differentiation from testicular neoplasm is difficult and, in most cases, only \\ possible after surgical removal of the mass. High index of suspicion, especially in slowly \\ growing scrotal mass in men older than 50 years, is required to diagnose this pathology and \\ prevent unnecessary orchiectomy. \\ Conclusion:Chronic scrotal hematocele is a rare pathologywith clinical and radiological \\ characteristics similar to testicular tumor, carful patient history taken is crucial to help in \\ proper management.
}

Keywords: chronic scrotal hematocele,scrotal swelling,testicular tumor,hematocele
Volume 4 Issue 5 - 2017

Mohammed Mahdi Babakri
Urology Unit,Aden University, Yemen

Correspondence: Mohammed Mahdi Babakri, Urology Unit, Surgical Department, Faculty of Medicine and Health Sciences, Aden University, Khormaksar, Yemen, P O Box 6038, Tel 00967 777401971, Fax 009672232298 ,

Email drburakturgut@gmail.com

Received: March 08, 2017 | Published: April 25, 2017

\section{Introduction}

The differential diagnosis of scrotal swellings is long and includes both benign and malignant conditions. Hematocele is a collection of blood between the parietal and visceral layers of the tunica vaginals of the testis, it could follow trauma or surgery to the scrotum, and however it is the role rather than the exception that in chronic hematocele no specific event could be recalled by the patient for that it is called "idiopathic scrotal hematocele. ${ }^{1}$ The slowly progressive nature of the chronic scrotal hematocele with little or no pain and the physical and radiological characteristics of the mass make the differentiation from testicular neoplasms very difficult and in most cases, the exact nature of the problem not clearly identified until the testis has removed. ${ }^{2-4}$ Scrotal ultrasound (US) is usually the first imaging modality used to evaluate the scrotum; the sonographic picture is that of heterogeneous mass of cystic component with septation and varying degreesof calcifications raising a high possibility of testicular mass. ${ }^{5}$ There is paucity in the world literature about this conditions and only scattered case reports published here and there. To the best of our knowledge, this is the first review article about chronic hematocel of the scrotum.

\section{Method}

Medline database searched using a combination of the key words: "chronic hematocele", "hematocele" and "scrotal hematocele"by January 2017 no language or date restriction imposed, although English language and more recently published articles are preferred. All relevant articles reviewed extensively for the clinical, radiological, surgical and histopathological characteristics. Additionally relevant references from these articles also reviewed and included. The author's own cases (one published and another one not published yet is included in this review). ${ }^{6}$

\section{Ethical consideration}

The author respect all ethical regulations regarding biomedical research, since the study not involve experiment on humans or animals no ethical committee approval needed.

\section{Result and discussion}

From the 502 retrieved titles, only 48 are relevant to the subject studied whose abstracts examined and another 16 irrelevant abstracts excluded (Figure 1). Chronic scrotal hematocele is a rare condition with only 35 cases reported so far in the known world literature, few scattered case reports published in medical journals of different languages with a maximum of two cases reported by some authors. ${ }^{7,4}$

\section{Clinical picture}

Clinically, hematocele present as slowly progressing, usually non tender scrotal mass which is difficult to transilluminate, the duration of the swelling varies from few months to several decades. ${ }^{2,3,6,8}$ There is usually no pain but a discomfort or heaviness is not uncommon in the scrotum. Chronic scrotal hematocel can affect every age group; the older age group was the most affected ones. ${ }^{8,9}$

\section{Imagining}

Scrotal ultrasound (US)is the diagnostic modality for scrotal 
pathologies, the examination usually reveal mixed heterogeneous mass with both solid and cystic components ${ }^{5}$ a findings which cannot rule out testicular or paratesticular tumor. Cunningham (1983) finds septation is a consistent findings in both acute and chronic hematoceles, ${ }^{10}$ magnetic resonance imaging (MRI) is more specific but not diagnostic and when MRI performed for chronic hematocele itreveal encapsulated mass with high signal intensity in both $\mathrm{T} 1$ and T2 images. ${ }^{3,11,12}$

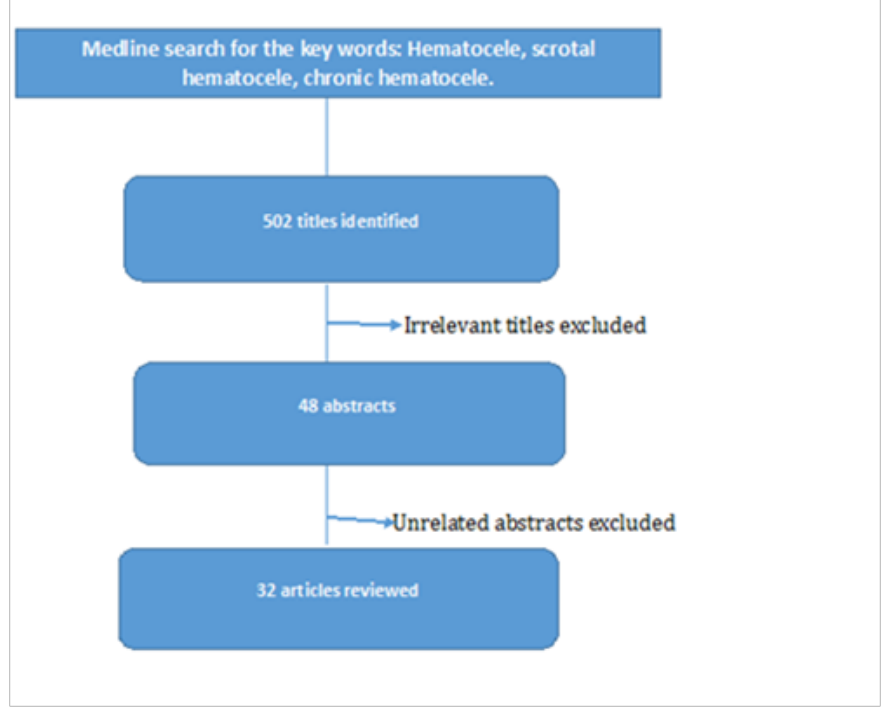

Figure I Flow chart showing the steps of literature search.

\section{Surgical management}

The nature of the pathology was only clear after surgery and histopathological examination of the removed testis in almost all of the cases reported.Surgical exploration and orchiectomy almost universally performed. ${ }^{1-4,6-15}$ The long duration and slow progression of the swelling over years and, even decades in some cases should arise the suspicion of hematocele. ${ }^{3}$ The effect of hematocele on the testis is deleterious leading to atrophy and even complete disappearance, ${ }^{6}$ this usuallythe result of long standing compression effect of the hematoma, sometimes superimposed infection of the hematocele complicates the situation more. ${ }^{13} \mathrm{Chronic}$ scrotal hematocele develops gradually over several years or decades, it tends to occur in older persons more often. ${ }^{14,15}$ Testicular germ cell tumors tend to occur in younger population.

\section{Histopathology}

Histological examination of the surgically removed mass is the diagnostic proof of the benign nature of the condition, typically there chronic inflammatory cells predominantly eosinophils and hemosiderin laden macrophages. Cholesterol crystals also commonly seen. ${ }^{12,4}$

\section{Conclusion}

Chronic scrotal hematocele is rare entity;high index of suspicion is required to diagnose this rare condition. Early recognition and management may prevent the inevitable loss of the testis.

\section{Acknowledgments}

None.

\section{Conflicts of interest}

None.

\section{References}

1. J Madan, U Madan. Idiopathic Chronic Hematocele of the Scrotum. internet J Surg. 2006;11(1):6-8.

2. Jain S, Garg R, Sarangi R. Chronic hematocele of testis - A mimicker of tumor. Curr Med Res Pract. 2015;5(2):72-74.

3. Barale M, Oderda M, Faletti R, et al. The strange case of a hematocele mistaken for a neoplastic scrotal mass. J Can Urol Assoc. 2015;9(34):217-219.

4. Minagawa T, Hirabayashi N, Furuhata M, et al. Two cases of an intrascrotal cystic mass mimicking a testicular tumor and review of the literature. Hinyokika Kiyo. 2006;52(4):311-314.

5. Patil V, Shetty SMC, Das S. Common and Uncommon Presentation of Fluid within the Scrotal Spaces. Ultrasound Int Open. 2015;1:34-40.

6. Mohammed Mahdi Babakri. Chronic hematocele with complete testicular autolysis. J Trop Nephrourol. 2011;10(6):34-35.

7. Bohorquez CL, Porras V. Casos Clínicos Correspondencia. Arch Esp Urol. 2007;61(4):537-540.

8. Aoki M, Ishikawa A, Ushiyama $\mathrm{T}$, et al. A case of chronic scrotal hematocele. Hinyokika Kiyo. 1995;41(10):817-819.

9. Mitsuhashi M, Nakatani T, Wada S, et al. A case of organized scrotal hematocele with high serum CA19-9 level. Hinyokika Kiyo. 2003;49(4):231-234.

10. Cunningham JJ. Sonographic findings in clinically unsuspected acute and chronic scrotal hematoceles. Am J Roentgenol. 1983;140(4): 749-752.

11. Alvarez-Alvarez C, Farina-Perez LA, Barros CR. Idiopathic chronic hematocele of the vaginal SAC. Int Braz J Urol. 2005;31(6):555-557.

12. Klimis T, Alexandris I, Kyriakidis A, et al. A Case of Chronic Huge Scrotal Hematocele. Internet J Surg. 2013;30(4):1-4.

13. Pascual Regueiro D, García de Jalón Martínez A, Trívez Boned MA, et al. Infected giant idiopathic haematocele. Actas Urológicas Españolas España. 2003;27(8):645-648.

14. Moriyama M, Yokoi K, Tsugawa R, et al. A case of chronic scrotal hematocele. Hinyokika Kiyo. 1996;42(7):543-545.

15. Koh E, Kondoh N, Kiyohara H, et al. A case of chronic huge hematocele. Acta Urol Jpn. 1989;35(8):1421-1444. 